

\title{
Spectroscopy of YAl3(BO3)4:Cr3+ crystals following first principles and crystal field calculations
}

Iwan V. Kityk, Mikhail Brik, Leszek Jaroszewicz, Artur Wojciechowski, Andrzej Majchrowski

\section{> To cite this version:}

Iwan V. Kityk, Mikhail Brik, Leszek Jaroszewicz, Artur Wojciechowski, Andrzej Majchrowski. Spectroscopy of YAl3(BO3)4:Cr3+ crystals following first principles and crystal field calculations. Philosophical Magazine, 2010, 90 (34), pp.4569-4578. 10.1080/14786435.2010.515265 . hal-00628681

\section{HAL Id: hal-00628681 \\ https://hal.science/hal-00628681}

Submitted on 4 Oct 2011

HAL is a multi-disciplinary open access archive for the deposit and dissemination of scientific research documents, whether they are published or not. The documents may come from teaching and research institutions in France or abroad, or from public or private research centers.
L'archive ouverte pluridisciplinaire HAL, est destinée au dépôt et à la diffusion de documents scientifiques de niveau recherche, publiés ou non, émanant des établissements d'enseignement et de recherche français ou étrangers, des laboratoires publics ou privés. 




\section{Spectroscopy of YAl3(BO3)4:Cr3+ crystals following first principles and crystal field calculations}

\begin{tabular}{|r|l|}
\hline Journal: & Philosophical Magazine \& Philosophical Magazine Letters \\
\hline Manuscript ID: & TPHM-10-May-0172.R1 \\
\hline Journal Selection: & Philosophical Magazine \\
\hline Author: & 11 -Jun-2010 \\
\hline Complete List of Authors: & $\begin{array}{l}\text { Kityk, Iwan; Czestochowa University of Technology, Electrical } \\
\text { Engineering } \\
\text { Brik, Mikhail; Tartu University, Physical } \\
\text { Jaroszewicz, Leszek; Miitary University Technology, Applied Physics } \\
\text { Wojciechowski, Artur; Czestochowa University Technology, Elecrical } \\
\text { Engineering } \\
\text { Majchrowski, Andrzej; Miitary University Technology, Applied } \\
\text { Physics }\end{array}$ \\
\hline Keywords: & optical properties, optical spectroscopy \\
\hline Keywords (user supplied): & \\
\hline &
\end{tabular}

\section{S ScholaroNE \\ Manuscript Central}


Spectroscopy of $\mathrm{YAl}_{3}\left(\mathrm{BO}_{3}\right)_{4}: \mathrm{Cr}^{3+}$ crystals

following first principles and crystal field calculations

by M.G.Brik, A.Majchrowski*, L.Jaroszewicz*, A.Wojciechowski**, I.V.Kityk**

Institute of Physics, University of Tartu, Riia 142, Tartu 51014, Estonia

* Institute of Applied Physics, Military University of Technology, Kaliskiego 2, 00-908 Warsaw, Poland

**Electrical Engineering Department. Czestochowa University Technology, Armii Krajowej 17, Czestochowa, Poland

Abstract:

The CASTEP module of Materials Studio package was used for calculations of the structural, electronic and optical properties of pure and $\mathrm{Cr}^{3+}$-doped YAB. The exchange-correlation effects were treated within the generalized gradient approximation (GGA) with the Perdew-Burke-Ernzerhof functional. The Monkhorst-Pack scheme $k$-points grid sampling was set at $3 \times 3 \times 4$ for the Brillouin zone (BZ). The plane-wave basis set energy cutoff was set at $340 \mathrm{eV}$; ultrasoft pseudopotentials were used for all chemical elements. The convergence parameters were as follows: total energy tolerance $1 \times 10^{-5} \mathrm{eV} /$ atom, maximum force tolerance $0.03 \mathrm{eV} / \mathrm{nm}$, maximal stress component $0.05 \mathrm{GPa}$ and maximal displacement $0.001 \AA$. Identification of the principal absorption peaks of the studied crystal was done. Influence of the $532 \mathrm{~nm}$ cw $300 \mathrm{~mW}$ laser beams on the observed absorptions is studied.

\section{Introduction}

The rare earth doped $\mathrm{YAl}_{3}\left(\mathrm{BO}_{3}\right)_{4}$ (YAB) single crystals are of particular interest due to existence of an interesting physical properties like incommensurate phase [1]; possibility to obtain nanopowder phosphors [2], defect - induced phase transitions [3] existence of up- and down-conversions [4]. Particular interest present the Cr doped YAB crystals. In particularly in the Ref. 5 it was found the piezo-induced second-order nonlinear optical effect in polyvinyl alcohol/YAB:Cr nanocomposites and influence of $\mathrm{YAB}: \mathrm{Cr}^{3+}$ nanocrystallite sizes [6]. These materials are of special interest for the light emitting diodes [7]. These crystals have a broad fluorescence ranging from the red to near-IR spectral region, and their lifetimes were measured as $170 \mu \mathrm{s}$ and $87 \mu \mathrm{s}$, respectively. The emission cross sections are estimated to be $0.8 \times 10^{-20}$ and $1.6 \times 10^{-20} \mathrm{~cm}^{2}$, respectively. The vibronic levels of their ground state were estimated to be $\approx 1400 \mathrm{~cm}^{-1}$, so they can provide a four-level system [8]. The optical gain of $\mathrm{Cr}^{3+}: \mathrm{YAB}$ crystal was measured in the range from $744 \mathrm{~nm}$ to $852.5 \mathrm{~nm}$. The maximum single-pass gain was 1.9 at $830 \mathrm{~nm}$. Second harmonic generation in the UV region $(375 \mathrm{~nm})$ was obtained by a $\mathrm{Cr}^{3+}: \mathrm{YAB}$ 
crystal with 1.5 times higher conversion efficiency compared with LBO crystal. Consequently $\mathrm{Cr}^{3+}: \mathrm{YAB}$ crystal and $\mathrm{Cr}^{3+}: \mathrm{YGAB}$ crystal have potential as new optically operated materials [9]. To vary the properties of the crystals in the desired direction it is necessary to have the parameters of the band energy structure for the crystals doped by the dopants. This can help to clarify the transfer of the carrier during the interaction with laser beam. In the Ref. 10. it was performed their band structure calculations. However, it would be of great interest to perform the calculation with taking into account of the doping by $\mathrm{Cr}$ ions.

In the present work we will do such kind of calculations taking into account of the influence of Chromium ions on the band structure. In the second part are presented the methods of crystal growth and principal features of the crystals. Section 3 describes first methods of principle calculations of the band energy structure. The principal results of the band energy structure calculations and corresponding photoinduced experimental data are given in the Section 4.

\section{Crystal growth and crystal features.}

$\mathrm{YAl}_{3}\left(\mathrm{BO}_{3}\right)_{4}$ single crystals belong to the $\mathrm{R} 32 \mathrm{H}$ space group with lattice constants (in $\AA$ ): $a=9.293$, $c=7.236, \gamma=120^{\circ}$ [11]. The $\mathrm{YAB}: \mathrm{Cr}$ single crystals were synthesized by means of spontaneous crystallization. $\mathrm{YAB}$ decomposes at $1280^{\circ} \mathrm{C}$ into $\mathrm{YBO}_{3}$ and $\mathrm{AlBO}_{3}$ due to incongruent melting [12], so crystallization had to be carried out from high-temperature solution. Potassium trimolybdate $\mathrm{K}_{2} \mathrm{Mo}_{3} \mathrm{O}_{10}$ with addition of $3 \mathrm{wt} \%$ of $\mathrm{B}_{2} \mathrm{O}_{3}$ was used as a solvent [13]. The starting composition of the melt was $20 \mathrm{wt} \%$ of YAB doped with 1 at $\%$ of $\mathrm{Cr}^{3+}$ ions and $80 \mathrm{wt} \%$ of the molybdate solvent. The growth was carried out from $200 \mathrm{~g}$ of the melt placed in a $100 \mathrm{ml}$ Pt crucible covered with a Pt lid under conditions of low-temperature gradients. The crucible was placed in a resistance furnace isolated thermally to ensure proper temperature gradients. The heating zone of the furnace was controlled with use of Eurotherm 916S programmer. The soaking temperature of the melt was $1100^{\circ} \mathrm{C}$, after 24 hours the temperature was lowered at a rate of $10 \mathrm{~K} / \mathrm{h}$ to $1050^{\circ} \mathrm{C}$ that is the saturation temperature of the melt. Next the temperature was lowered at a rate of $0.1 \mathrm{~K} / \mathrm{h}$ for 58 days and then the furnace was cooled at a rate of $10 \mathrm{~K} / \mathrm{h}$ to room temperature. The as-grown $\mathrm{YAB}: \mathrm{Cr}^{3+}$ single crystals (up to 10x10x10 mm) were extracted from the solidified melt by dissolution of the solvent in hot water. According to Ref. [14], the distribution coefficient of $\mathrm{Cr}^{3+}$ ions between $\mathrm{YAB}$ crystal and the melt is very high and reaches 9.7, what caused non-uniform distribution of the dopant in as-grown crystals. $\mathrm{The}^{\mathrm{Cr}^{3+}}$ concentration in the central parts of $\mathrm{YAB}: \mathrm{Cr}^{3+}$ crystals was much higher than in the starting composition, and then it decreased towards the faces of the crystals. The photoinduced $532 \mathrm{~nm} \mathrm{cw}$ laser at wavelength possesses Gaussian-like sequence beam with diameter about $1.5 \mathrm{~mm}$. Its intensity 


\section{First-principles calculations for pure and $\mathrm{Cr}^{3+}$-doped $\mathrm{YAl}_{3}\left(\mathrm{BO}_{3}\right)_{4}$}

The CASTEP module [15] of Materials Studio package was used for calculations of the structural, electronic and optical properties of pure and $\mathrm{Cr}^{3+}$-doped $\mathrm{YAB}$. The exchange-correlation effects were treated within the generalized gradient approximation (GGA) with the Perdew-BurkeErnzerhof functional [16]. The Monkhorst-Pack scheme $k$-points grid sampling was set at $3 \times 3 \times 4$ for the Brillouin zone (BZ). The plane-wave basis set energy cutoff was set at $340 \mathrm{eV}$; ultrasoft pseudopotentials were used for all chemical elements. The convergence parameters were as follows: total energy tolerance $-1 \times 10^{-5} \mathrm{eV} /$ atom, maximum force tolerance $0.03 \mathrm{eV} / \mathrm{nm}$, maximal stress component $0.05 \mathrm{GPa}$ and maximal displacement $0.001 \AA$.

\section{Results of calculations.}

The calculated lattice constants after optimization of the crystal lattice structure were as follows (in $\AA$ ): $a=9.25562, c=7.22184, \gamma=120^{\circ}$. The difference between the calculated and experimental lattice parameters is less then $1 \%$. Fig. 1 shows the calculated band structure (the conduction and valence bands only) for pure YAB. The low dispersion for the upper valence band indicate on the huge effective mass of the holes formed prevailingly by the antibonding $2 \mathrm{pO}-2 \mathrm{pC}$ states. Experimental value of the band gap is $5.7 \mathrm{eV}$ [17], and the calculated value of the band gap was $5.471 \mathrm{eV}$, which is a little bit underestimated with respect to the experimental value. Such an underestimation of the calculated band gaps is related to well-known DFT limitations, namely not taking into account the discontinuity in the exchange-correlation potential [18], and is a common feature of all DFT calculations. To overcome such a discrepancy, the so called scissor operator [19] can be used. The action of such an operator is to produce a simple rigid shift of the unoccupied conduction band with respect to the valence band, to eliminate effectively the difference between the theoretical and experimental gap values. Usually the values of this operator can be around $1-1.5 \mathrm{eV}$. However, since in this case the difference between the two values of the band gap was only about $0.23 \mathrm{eV}$, we decided not to apply the scissor operator and thus we remain entirely within the framework of the ab initio calculations. 


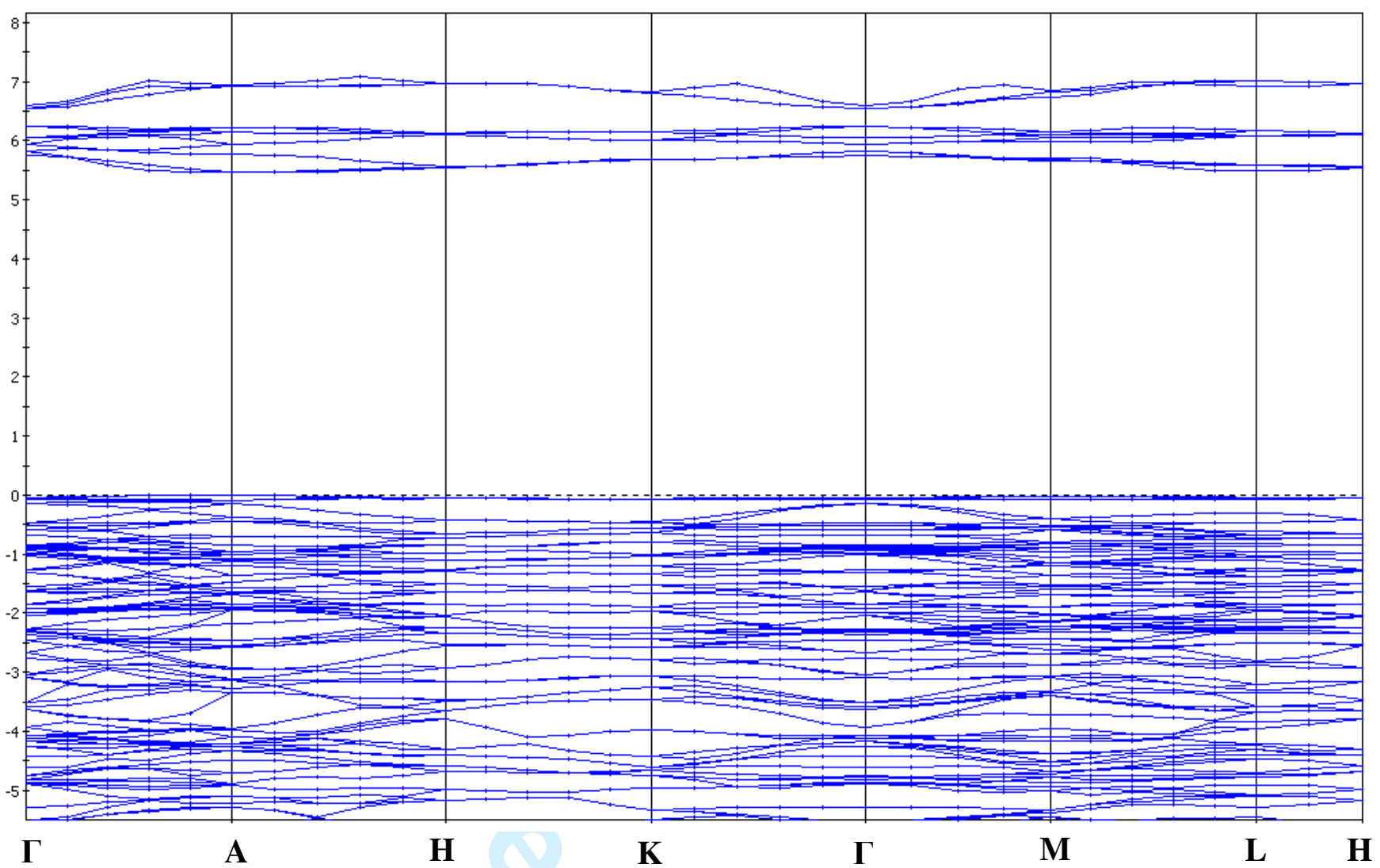

Fig. 1. Calculated band structure of pure YAB. The coordinates of the special points of the Brillouin zone are (in terms of the unit vectors of reciprocal lattice: $\Gamma(0,0,0)$; $\mathrm{A}(0,0,1 / 2), \mathrm{H}(-1 / 3,2 / 3,1 / 2)$; $\mathrm{K}(-1 / 3,2 / 3,0) ; \mathrm{M}(0,1 / 2,0) ; \mathrm{L}(0,1 / 2,1 / 2)$.

It is necessary to emphasize that the k-dispersion of the valence bands is very flat which corresponds to huge effective mass and low carrier mobility. The higher dispersion is observed in the BZ direction: $\mathrm{K}-\Gamma-\mathrm{M}$. Assignment of the calculated bands can be performed using the partial density of states (PDOS) diagrams, shown in Fig. 2. The conduction band, which is $2.5 \mathrm{eV}$ in wide, is composed mainly of Y 4d states, with some admixture of $\mathrm{Al} 3 \mathrm{p}, \mathrm{O}$ and B 2p delocalized states. The upper valence band, whose widths is about $8 \mathrm{eV}$, is formed by the $\mathrm{Al} 3 \mathrm{~s}, 3 \mathrm{p}, \mathrm{O} 2 \mathrm{p}, \mathrm{B} 2 \mathrm{~s}, 2 \mathrm{p}$ states. The lower valence band from about $-22 \mathrm{eV}$ to about $-17 \mathrm{eV}$ - has a clearly seen hyperfine structure. The lower narrow subband between -22 and $-20 \mathrm{eV}$ is due to $\mathrm{Y} 4 \mathrm{p}$ states, whereas the upper sub-band between -17 and -20 $\mathrm{eV}$ is a superposition of the $\mathrm{O} 2 \mathrm{~s}, \mathrm{Al} 3 \mathrm{~s}, 3 \mathrm{p}$ and $\mathrm{B} 2 \mathrm{~s}, 2 \mathrm{p}$ states. Finally, a very narrow and deep energy band between -40 and $-42 \mathrm{eV}$ is formed by the $\mathrm{Y} 4 \mathrm{~s}$ states. 


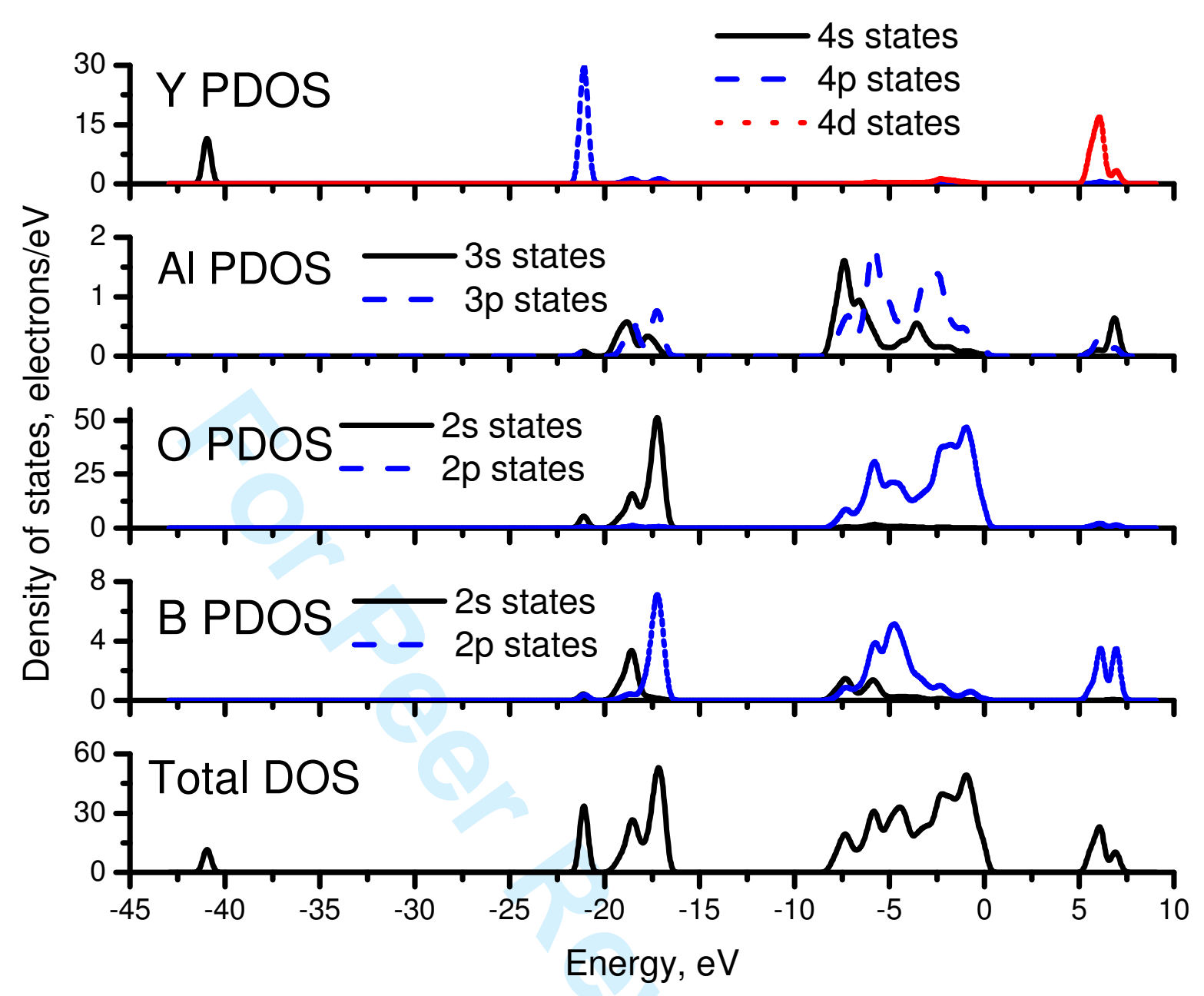

Fig. 2. Calculated partial and total density of states (DOS) for pure YAB. 


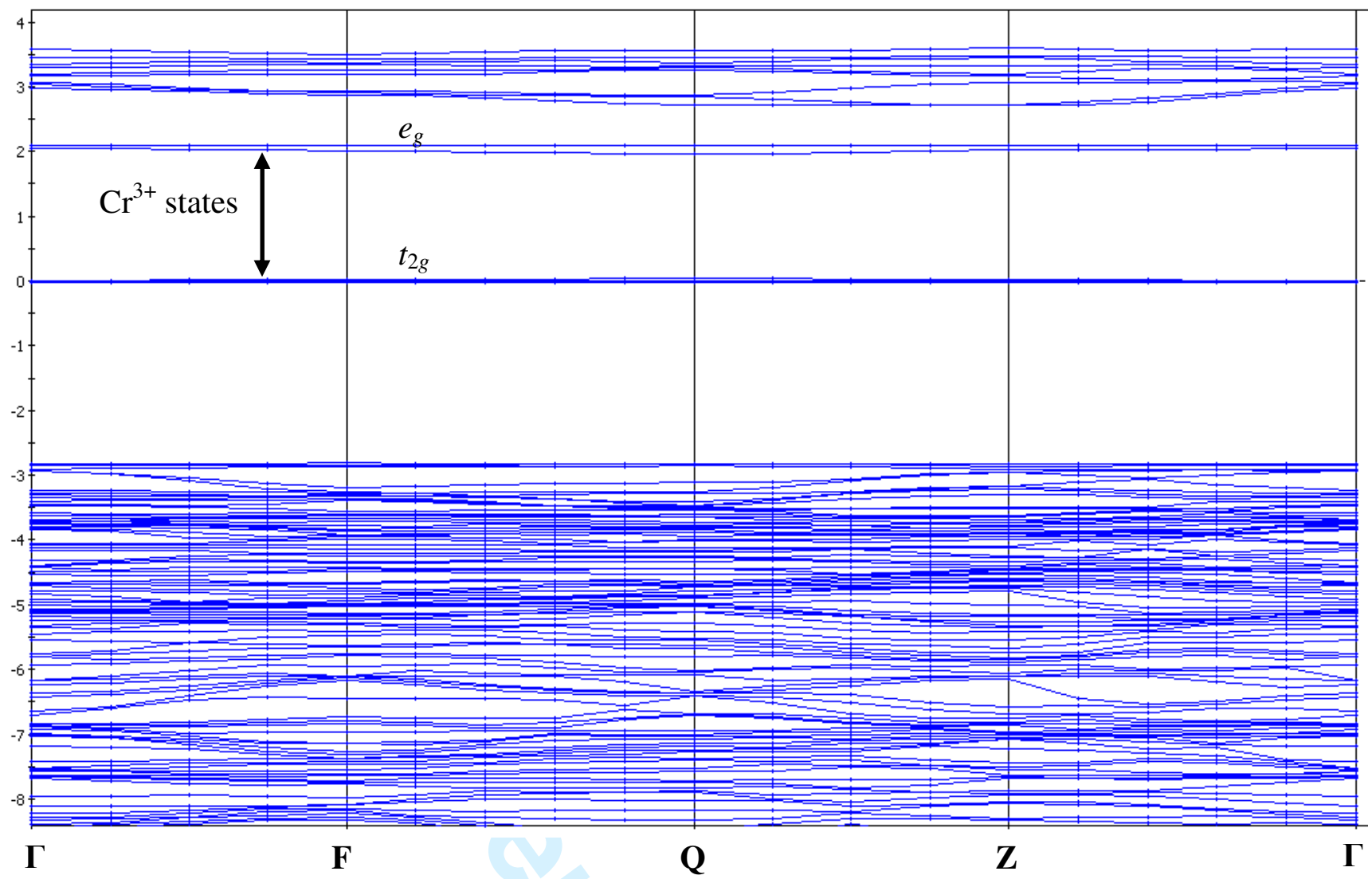

Fig. 3. Calculated band structure of the $\mathrm{YAB}: \mathrm{Cr}^{3+}$ crystal. The special points of the Brillouin zone are: $\Gamma(0,0,0)$; A $(0,0,1 / 2), \mathrm{H}(-1 / 3,2 / 3,1 / 2) ; \mathrm{K}(-1 / 3,2 / 3,0) ; \mathrm{M}(0,1 / 2,0) ; \mathrm{L}(0,1 / 2,1 / 2)$. The highest occupied state is taken as zero of energy.

Situation becomes different when doping with $\mathrm{Cr}^{3+}$ ions (which generally should substitute for $\mathrm{Al}^{3+}$ ions) is considered. First of all, the calculated lattice parameters become now (in $\AA$ ): $a=9.2932$, $b=9.2774, c=7.2575, \alpha=89.95^{\circ}, \beta=90.0^{\circ}, \gamma=120.08^{\circ}$. It is crucial that doping with $\mathrm{Cr}^{3+}$ leads to minor changes in the lattice constants. The Fig. 3 shows the calculated band structure for the YAB: $\mathrm{Cr}^{3+}$ crystal. The most striking difference from the previous case shown in Fig. 1 is that the $\mathrm{Cr}^{3+}$ states appear within the forbidden energy band gap. They possess some dispersion which is maximal Moreover, it is possible to distinguish between the $t_{2 g}$ and $e_{g}$ states, which arise from the crystal field splitting of the $\mathrm{Cr}^{3+} 3 \mathrm{~d}$ states and which are separated by about $2 \mathrm{eV}$ (Fig. 3). The maximal dispersion of these levels is observed for $\mathrm{F}-\mathrm{Q}-\mathrm{Z}$ direction. The localized $\mathrm{Cr}$ impurities are sensitive to the crystalline anisotropy. Such a separation is denoted by $10 \mathrm{Dq}$ and its value can be determined from the absorption spectra by the position of the first strong spin-allowed transition, which corresponds to the ${ }^{4} \mathrm{~T}_{2}$ state. Fig. 4 shows the PDOS diagrams. The composition of the calculated electronic bands is the same as for pure $\mathrm{YAB}$, but two very narrow deep bands appear at about $-44 \mathrm{eV}$ and $-72 \mathrm{eV}$; they are due to the chromium $3 \mathrm{p}$ and $3 \mathrm{~s}$ states, respectively. 


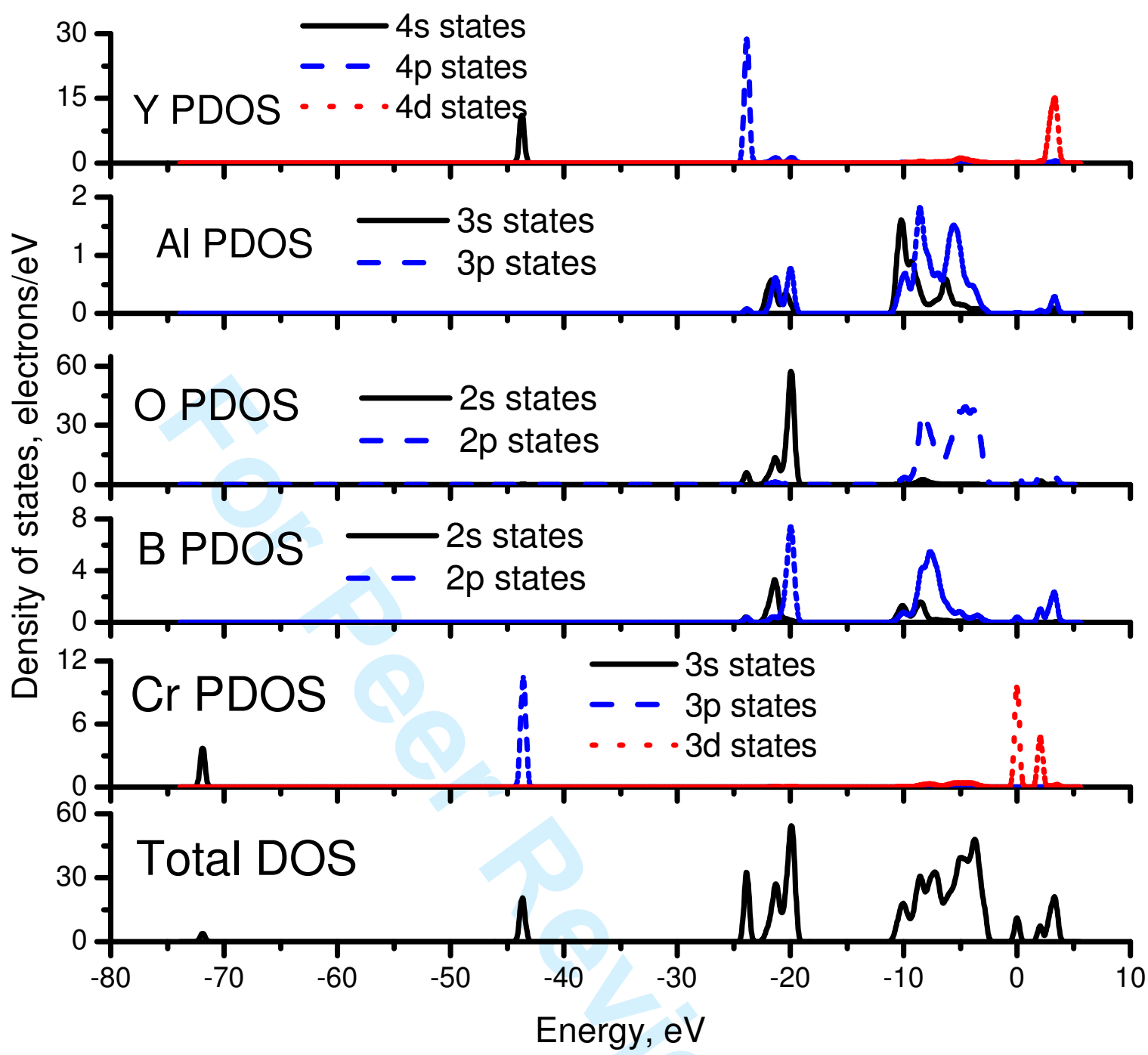

Fig. 4. Calculated partial and total density of states for $\mathrm{YAB}: \mathrm{Cr}^{3+}$.

For an analysis of the absorption spectra of the $\mathrm{Cr}^{3+}$-doped $\mathrm{YAB}$, crystal field theory (namely, exchange charge model, ECM [20]) has been used.

Since detailed description of this model can be found in the literature [21], we shall not give here description of the model and its main equations, but restrict ourselves to mentioning the details of calculations and obtained results. To calculate the crystal field parameters, a large cluster of 31793 ions located at the distances up to $73 \AA$ from the central ion was considered. The overlap integrals between the $\mathrm{Cr}^{3+}$ and $\mathrm{O}^{2-}$ ions were calculated previously [27]. The calculated values of the crystal field parameters (in Stevens normalization, all in $\mathrm{cm}^{-1}$ ) are as follows:

Values of the crystal field and $B_{4}^{-4}=1422.0 ; B_{4}^{-3}=-3.5 ; B_{4}^{-2}=994.0 ; B_{4}^{-1}=1564.0 ; \quad B_{4}^{0}=-3259 ; B_{4}^{1}$ $=902.8 ; \quad B_{4}^{2}=-573.9 ; \quad B_{4}^{3}=-77950.4 ; \quad B_{4}^{4}=822.0 ; \quad B_{2}^{-2}=294.9 ; \quad B_{2}^{-1}=-334.5: B_{2}^{0}=3098.0 ; \quad B_{2}^{1}=-194.3$; $B_{2}^{2}=-170.8$. The crystal field Hamiltonian with these parameters was diagonalized in the space 
spanned by all LS wave functions of the LS terms of the $3 \mathrm{~d}^{3}$ electron configuration of $\mathrm{Cr}^{3+}$ ion. The Racah parameters $B$ and $C$ were chosen to be 700 and $3163 \mathrm{~cm}^{-1}$, respectively. The calculated energy levels are given below (all in $\mathrm{cm}^{-1}$ ). The spin-quartet energy levels: ${ }^{4} \mathrm{~A}_{2}-0 ;{ }^{4} \mathrm{~T}_{2}-16439,16451,17254$; ${ }^{4} \mathrm{~T}_{1}\left({ }^{4} \mathrm{~F}\right)-22672,24155,24171 ;{ }^{4} \mathrm{~T}_{1}\left({ }^{4} \mathrm{P}\right)-35855,35947,39538$. The spin-doublet energy levels: ${ }^{2} \mathrm{E}-$ 14471, 14489; ${ }^{2} \mathrm{~T}_{1}-15112,15129,15677 ;{ }^{2} \mathrm{~T}_{2}-20994,22383,22498 ;{ }^{2} \mathrm{~A}_{1}-28958$; then very dense group of energy levels arising from the orbital triplets and doublets: 30884, 30927, 31052, 31464, $31673,31818,33612,33724 \mathrm{~cm}^{-1}$.

The character of splitting of the orbital triplets and doublets suggests a low symmetry of the $\mathrm{Cr}^{3+}$ position $\left(\mathrm{C}_{1}\right)$. However, splitting of the orbital doublets is very small, and in all triplet states it is possible to find a group of two very closely located energy levels and a single level, lying far apart from this group. Such a splitting pattern suggests that the local symmetry of the $\mathrm{Cr}^{3+}$ position can be approximately described as a trigonal, when a triplet state is split into the doublet and singlet. Such a conclusion can be also verified by the values of the crystal field parameters: the main contribution comes from the $B_{2}^{0}, B_{4}^{0}, B_{4}^{3}$ parameters, which are characteristic for a trigonal crystal field. Moreover several contribution here should gie the broadening caused by electron-phononinteractions and occurrence of non-homogenuities.

Fig. 5 below shows the experimental absorption spectrum of $\mathrm{YAB}: \mathrm{Cr}^{3+}$, in comparison with the above-given calculated energy levels. Following the performed X-ray micoranalysis these spectra correspond to the $0.85 \%$ of $\mathrm{Cr}^{3+}$ ions. However, there exists some non-uniformity through the sample's surface (from $0.65 \%$ up to $1.05 \%$ ). So we present the averaged spectrum of the absorption.

Following this figure, agreement between the positions of the calculated energy levels and main features of the absorption spectrum is good. In particular, narrow peaks at about $14800-15100 \mathrm{~cm}^{-1}$ nicely agree with the calculated positions of the spin doublets ${ }^{2} \mathrm{E}$ and ${ }^{2} \mathrm{~T}_{1}$. Calculated splitting of the ${ }^{4} \mathrm{~T}_{2}$ state (between 16400 and $17250 \mathrm{~cm}^{-1}$ ) agrees with the width of the first spin-allowed absorption band. Moreover, the ECM calculated position of the ${ }^{4} \mathrm{~T}_{2}$ state is in a very good agreement with the estimation of the $10 D q$ parameter obtained from the band structure calculations for $\mathrm{YAB}: \mathrm{Cr}^{3+}\left(\mathrm{Fig}^{3}\right.$. 3). Two wide intensive peaks at about 33000 and $37000 \mathrm{~cm}^{-1}$ are due to the superposition of transitions from the ${ }^{4} \mathrm{~A}_{2}$ ground state to the ${ }^{4} \mathrm{~T}_{1}\left({ }^{4} \mathrm{~F}\right)$ state and a very dense group of the spin doublet states, which are mixed up with the ${ }^{4} \mathrm{~T}_{1}\left({ }^{4} \mathrm{~F}\right)$ state by spin-orbit interaction. 


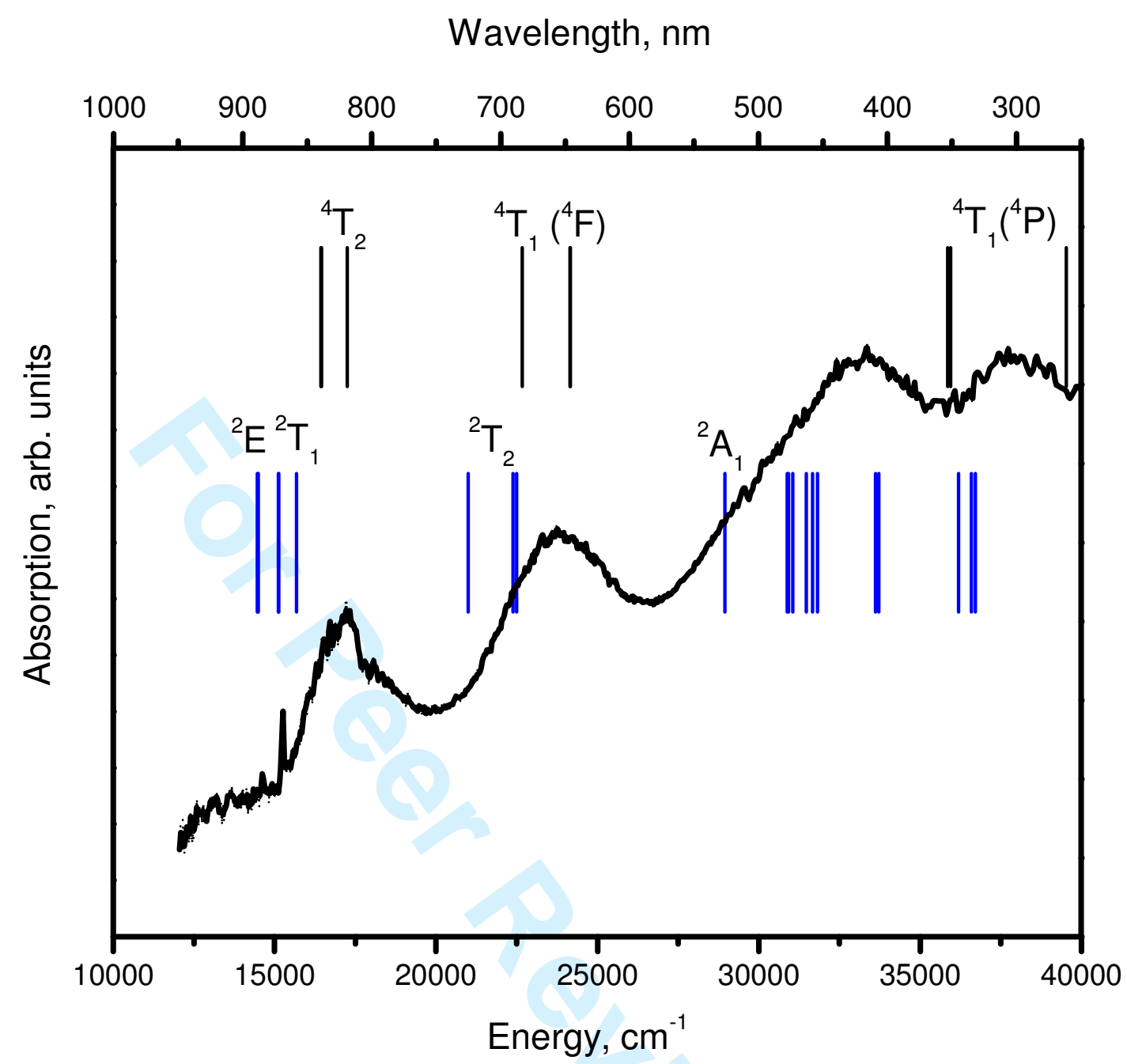

Fig. 5. Experimental absorption spectrum of $\mathrm{YAB}: \mathrm{Cr}^{3+}$ (solid line) and calculated energy levels (vertical lines). Assignment of the dense group of the spin doublet states in the region above $30000 \mathrm{~cm}^{-}$ ${ }^{1}$ is ambiguous.

Following the absorption spectra we have verified their sensitivity to the illumination by 300 $\mathrm{mW}$ SHG of the Nd:YAG laser with wavelength $532 \mathrm{~nm}$. Following the Fig. 6 one can say that the changes are very small. So these crystal may be promising for the high intensive nonlinear optical interactions. The obtained parameters show that the $\mathrm{Cr}$ ions change not only the energy positions of the bands, however cause an influence on the band dispersion. Additional monitoring of the photocrystallization does not show any signs of crystallization. 

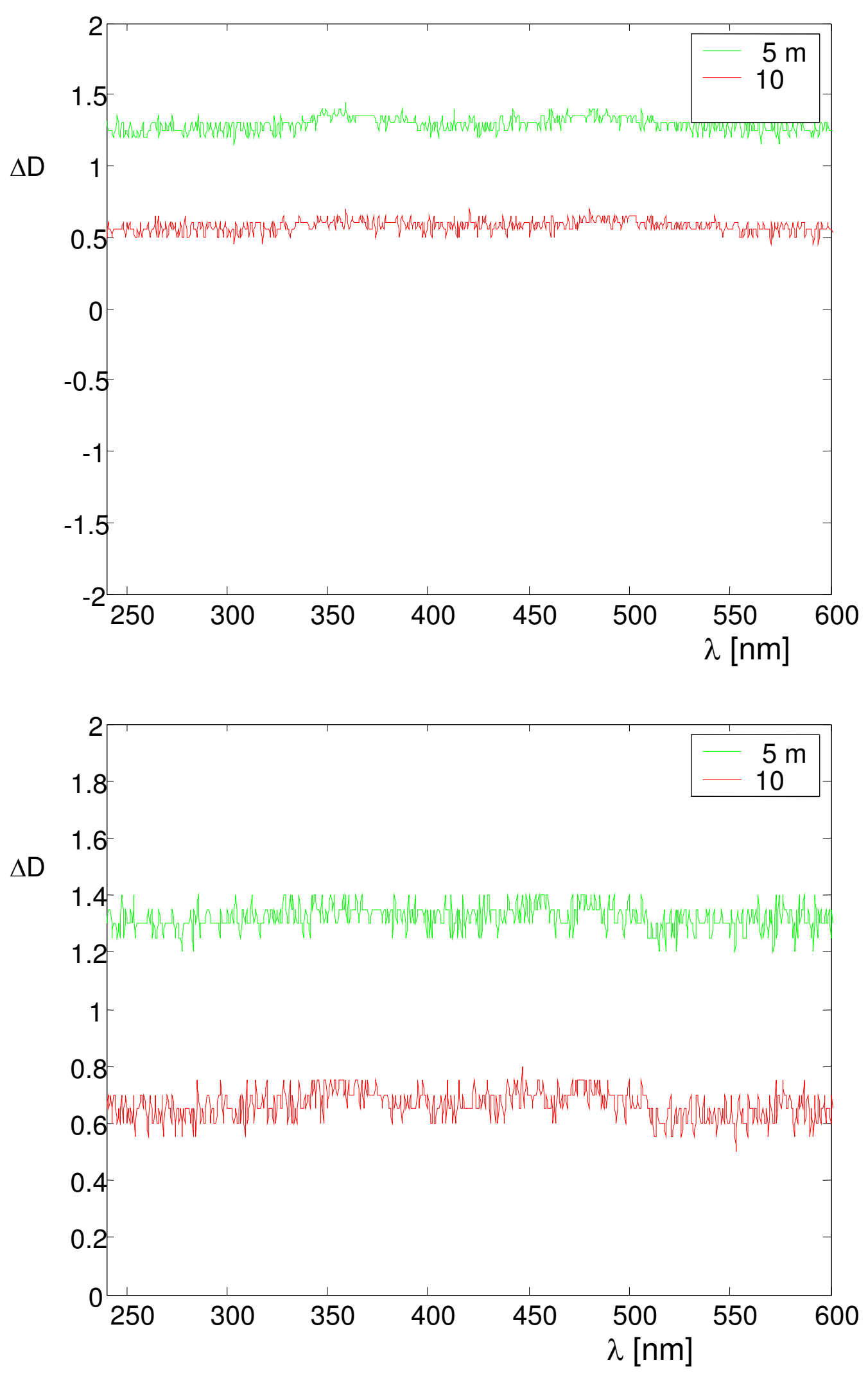

Fig. 6. Changes of the absorption caused by illumination of $532 \mathrm{~nm} \mathrm{cw}$ laser with power $300 \mathrm{~mW}$ in the points corresponding to two different $\mathrm{Cr}$ contents. 


\section{References:}

I. T. Bodnar, V. V. Filippov, N. V. Kuleshov, N. I. Leonyuk, V. V. Mal'tsev and O. V. Pilipenko. Inorganic Materials, 44, (2008), 863.

2. A. Szysia , L. Lipińska, W. Ryba-Romanowski, P. Solarz, R. Diduszko and A. Pajączkowska. Materials Res. Bulletin, 44, (2009), 2228.

3. A. Majchrowski \& I.V. Kityk. Ferroelectrics Letters. V.29, (2002), pp. 31-37.

4. G. Dominiak-Dzik, W. Ryba-Romanowski, R. Lisiecki, I. Főldvári, E. Beregi. Optical Materials, 31, (2009), 989.

5. A. Majchrowski, J. Ebothe, B.Sahraoui, I.V. Kityk. Nanotechnology,V.15, (2004),pp.118-1121. 
6. A.Majchrowski, I.V.Kityk, J.Ebothe. Phys.Status Solidi, V. B241, (2004), pp.3047-3055

7. Elmar C. Fuchs and Karl Gatterer. Central European Journal of Chemistry, 6, (2008), 497

8. Iwai, Makoto; Mori, Yusuke; Sasaki, Takatomo; Nakai, Sadao; Sarukura, Nobuhiko;

Liu, Zhenlin; Segawa, Yusaburo. Japanese Journal of Applied Physics, 34, (1995) pp. 2338 (1995).

9. Rajeev Bhatt, S. Kar, K. S. Bartwal, V. K. Wadhawan. Solid State Communications, 127, (2003), 457.

10. A.H.Reshak, S.Auluck, A.Majchrowski, I.V.Kityk. Solid State Sciences, V.10, (2008), pp.1445-1448.

11. G. Meszaros, E. Svab, E. Beregi, A. Watterich, M. Toth, Physica B 276 (2000) 310 12. S.F. Akhmetov, G.L. Akhmetova, V.S. Kovalenko, N.I. Leonyuk, A.V. Pashkova, Soviet-Phys. Dokl., 23 (1978) 107

13. G. Wang, H.G. Gallagher, T.P.J. Han, B. Henderson, J. Cryst. Growth, 153 (1995) 169 14. N.I. Leonyuk, E.V. Korpulina, J.Y. Wang, X.B. Hu,and A.V. Mokhov, J. Cryst. Growth, 252 (2003) 174

15. M.D. Segall, P.J.D. Lindan, M.J. Probert, C.J. Pickard, P.J. Hasnip, S.J. Clark, M.C. Payne, J. Phys.: Condens. Matter 14 (2002) 2717

16. J.P. Perdew, K. Burke, M. Ernzerhof, Phys. Rev. Lett. 77 (1996) 3865

17. A.H. Reshak, S. Auluck, A. Majchrowski, I.V. Kityk, PMC Physics B 1 (2008) 8

18. J.P. Perdew, M. Levy, Phys. Rev. Lett. 51 (1983) 1884

19. Z.H. Levine, D.C. Allane, Phys. Rev. B 43 (1991) 4187

20. B.Z. Malkin, in: A.A. Kaplyanskii, B.M. Macfarlane (Eds.), Spectroscopy of solids containing rare-earth ions, North-Holland, Amsterdam, (1987), 33-50

21. B.Z. Malkin, in: A.A. Kaplyanskii, B.M. Macfarlane (Eds.), Spectroscopy of solids containing rare-earth ions, North-Holland, Amsterdam, (1987), 33-50;

22. C. Jousseaume, D. Vivien, A. Kahn-Harari, B.Z. Malkin, Opt. Mater. 24 (2003) 143;

23. M.N. Popova, S.A. Klimin, E.P. Chukalina, R.Z. Levitin, B.V. Mill, B.Z. Malkin, E. Antic-Fidancev, J. Alloys Compds. 380 (2004) 84;

24. M.N. Popova, E.P. Chukalina, B.Z. Malkin, A.I. Iskhakova, E. Antic-Fidancev, P.

Porcher, J.P. Chaminade, Phys. Rev. B 63 (2001) 075103;

25. M.N. Popova, S.A. Klimin, E.P. Chukalina, E.A. Romanov, B.Z. Malkin, E. Antic-

Fidancev, B.V. Mill, G. Dhalenne, Phys. Rev. B 71 (2005) 024414;

26. A.V. Savinkov, D.S. Irisov, B.Z. Malkin, K.R. Safiullin, H. Suzuki, M.S. Tagirov, D.A. Tayurskii, J. Phys.: Condens. Matter 18 (2006) 6337

27. E. Cavalli, A. Belletti, M.G. Brik, J. Phys. Chem. Solids 69 (2008) 29. 